\title{
OVARIAN CYST FORMATION: MANY YEARS AFTER HYSTERECTOMY FOR HEMORRHAGIC COMPLICATIONS IN TWIN DELIVERY
}

\author{
Padhye S*, Karki C
}

\section{ABSTRACT}

After a subtotal hysterectomy for severe postpartum hemorrhage due to rupture uterus, following complication at internal podalic version and breech extraction for a second twin, in a primipara; a long term follow up and management by a wedge resection of ovary, ovariotomy, and removal of cyst was carried out by the same surgeon in three different Hospitals, so unique in our context, is reported.

\section{Key Words: TwinDelivery, Internal Podalic Version.}

\section{INTRODUCTION}

Internal podalic version for the second twin may at times complicate to uterine rupture and it becomes mandatory to perform subtotal hysterectomy with ovarian preservation a life saving procedure. One such case is reported.

\section{CASE STUDY}

In 1982, Mrs. N. J, aged 22 years, para one with a history of a stillbirth three months back, presented with a history of amenorrhoea of 40 days with negative urinary pregnancy test.

Uterine size increased to ten weeks in the next follow up visit and thereafter she was able to perceive fetal movements at 22 weeks of pregnancy. Considering her previous stillbirth, labor was induced at 39 weeks in Bir Hospital.

She delivered male baby by vertex presentation. Internal podalic version and delivery of second twin was completed in an hour, which lead to severe postpartum hemorrhage resulting in collapse within a few minutes after the placental delivery. Bleeding was not controlled with an ampoule I.V ergometrine. It was diagnosed to be uterine rupture, therefore she was resuscitated and taken to the general operation theatre and due to unavoidable delays of an hour or more, and the abdomen was finally opened on a single perineal sheet due to unavailability of proper seats, more over till the instruments were ready bleeding was arrested pinching on to the bleeders.

Subtotal hysterectomy was quickly done, preserving the ovaries. Indwelling Foley catheter was kept. Her recovery from anesthesia and the postoperative period were uneventful. She received twelve units of $\mathrm{AB}+\mathrm{ve}$ blood. She was discharged from Bir Hospital on $13^{\text {th }}$ postoperative day.

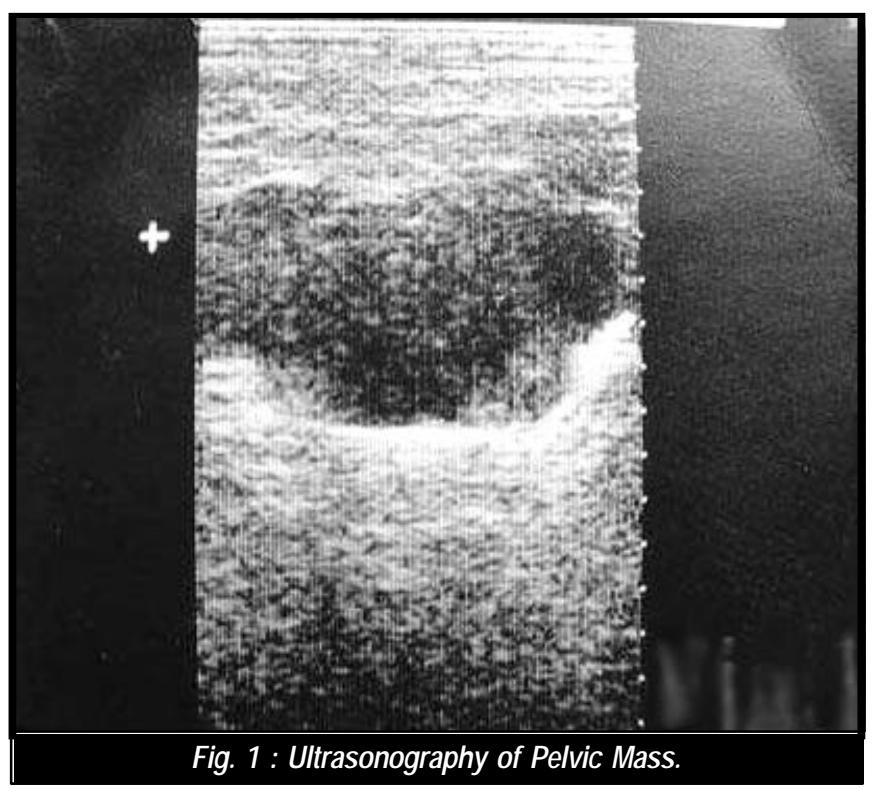

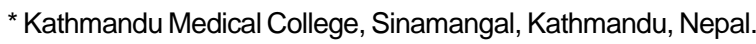

Address for correspondence : Prof. Saraswati Padhye

Kathmandu Medical College, Sinamangal, Kathmandu, Nepal.

Email: smpadhye@info.com.np 
After 9 years, she complained of loss of libido and dryness of vagina. A Pap smear was taken and estrogen tablets (evalon) $0.05 \mathrm{mg}$ was prescribed. After one month, she presented with a right cystic mass in the pelvis measuring 90x75-mm (Figure 1) by an ultra-sonogram, just available then in Nepal.

She was admitted for laparotomy at Maternity Hospital as the Ob/Gyn ward of Bir Hospital was closed down in 1985. Abdomen was opened with sub umbilical right para median incision; amidst dense adhesions where both ovaries were found to be cystic instead hydrosalpinix was seen on the left side. So wedge resection of right ovary \& left salpingectomy were performed. As per patient's request appendicectomy also was done. Her postoperative period was uneventful and was discharged on 12.5.048. Histology reported normal tube; inclusion cyst in the ovary and chronic appendicitis.

In the year 1994, heaviness of lower abdomen was the presenting complaints when the USG showed left cystic mass of $67 \times 55-\mathrm{mm}$ and a small solid structure of size 26x14 mm floating inside this cystic mass.

In, 1996, Trans-vaginal ultra-sonogram [by then available in Nepal] noted a cystic mass, $53 \times 48 \mathrm{~mm}$ on right side and 80 85 and $60-80 \mathrm{~mm}$ mass on to the left ovary, which had been gradually increasing in size over the preceding three years period; 1997-1999.

Consecutively the pelvic mass measured $72 \times 56 \mathrm{~mm}$ with solitary cyst of $35 \times 30 \mathrm{~mm}$, reported as "ovarian cyst (complex type)" with multiple internal septations finally increasing to $92 \times 68 \mathrm{~mm}$ to $107 \times 83 \mathrm{~mm}$ with vol. $390 \mathrm{cc}$ (Figure 2).

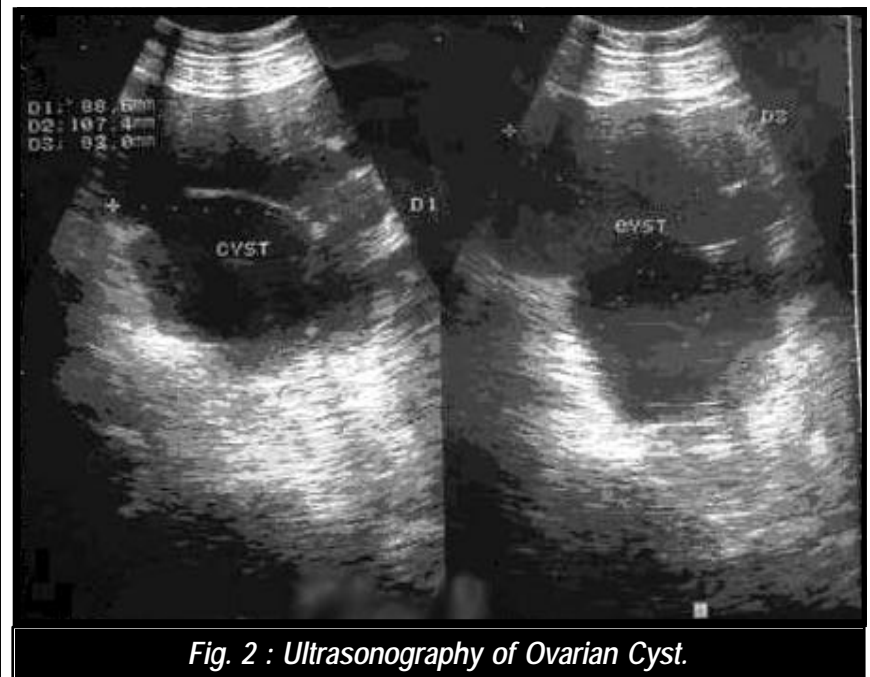

Mass about 10x10 $\mathrm{cm}$ on the right side of pelvis was felt with laxity in perineum and rectocele on the $3^{\text {rd }}$ admission at Katmandu Medical College when larger part of old abdominal scar was excised at laparotomy dissected off the adhesions. A multi-loculated thin walled cyst in the right side and some of

the cystic portion of the left ovarian tissues were removed maintaining the homeostasis.

The stump of the cervix was also removed; thereby completing the surgery after posterior colpoperiniorrhaphy.

The drainage tube and Foley's catheter were removed on the second day. Her postoperative recovery was satisfactory. She was discharged on request with premarine $0.625 \mathrm{mg}$. daily. After 13 days she attended the clinic with complaints of excessive vaginal discharge.

\section{DISCUSSION}

This case report is of historical importance being managed first of all in Bir Hospital and today only few of us know that, this hospital in the past exercised obstetrics and gynaecology services.

The other interesting part is that the same doctor, the first author has followed up the case for twenty long years in three different hospitals Bir /Maternity/Katmandu Medical College.

Before the Ultra-sonogram service was introduced by the pioneer Late Dr. Basanta Lal Shrestha in Nepal, clinical suspicion of multiple pregnancies were confirmed by Roentogram when it was safe to so.

Internal Podalic Version (IPV) is mainly performed in 2nd twin with transeverse lie accomplishing breech extraction. This procedure is done under general anesthesia when the cervix is fully dilated and the membranes are just ruptured. Failure to fulfill these prerequisites is apt to cause maternal death due to rupture of uterus.

The studies have shown that IPV carried out in $32.09 \%$ of 81 cases of shoulder presentation with fulfillment of prerequisites in a singleton pregnancy; reported one case of uterine rupture. ${ }^{1}$ The fetus was very premature or dead in utero.

Incidence of Rupture uterus can be as high as 1 in 330-500 deliveries and its contribution to the maternal and perinatal mortality can be 4.1 and $2.6 \%$ respectively. ${ }^{2}$ In a developing country the incidence can be as high as 1 in 96.6 deliveries $^{3}$

Emergency Peripartum Hysterectomies are being performed less than 24 hours after delivery in obstetrical practice, for hemorrhage unresponsive to other treatment like placenta praevia, rupture uterus, placenta accreta and atonic uterus. ${ }^{4,8}$ In a community teaching hospital placenta accreta was found to be the most common indication for emergency peripartum hysterectomy. ${ }^{5}$ More than $80 \%$ of these hysterectomies were 
of subtotal. ${ }^{5,6,8}$ There was significant decrease in mortality and morbidity due to this very reason in 1980-89 than in 197079. ${ }^{6}$ Even though the incidence of Rupture uterus is declining in some countries, its occurrence should be suspected if there is unexplained postpartum shock. ${ }^{7}$

Removal of Ovaries in young patients can give rise to menopausal syndrome; hence they are usually preserved although they stand at risk to the development of ovarian tumors 1 in 10,000.

\section{CONCLUSION}

Internal podalic version has to be discouraged even in a multiple pregnancy, if there is any doubt in its safety, now that the caesarean is undertaken even for the non-vertex presentation of any of the twins.

\section{REFERENCES}

1. Verma Purnima, Gupta P.L. 'Shoulder presentation, changing trends in its management in modern obstetrics" $J$ Obst Gynecol. 2001 March/April. 45: 6, 24-28.
2. Iloabachie GC, Agwu S. "The increasing incidence and declining mortality of rupture uterus in Enugu" J Obstet Gynaecol.1990 April. 10:4, $306-11$.

3. Kafkas S, Taner CE "Ruptured Uterus" Intemational J Gynaecol Obstet 1991 January 34: 1, 41-4.

4. Hamsho MA, Alsakka M " Emergency obstetric hysterectomy in Qatar: a 20 years review" International joumal of Fertil Womens Med 1999 June -August; 44: 4, 209-11.

5. Kastner ES, Figueroa R, Garry D, Maulik D. "Emergency peripartum hysterectoy: Experience at a community teaching Hospital". Obstet Gynecol 2002; June; 99:6, 971-5.

6. Nagarkatti RS, Ambie VR, Vaidya PR. "Rupture uterus changing trend in etiology and management" J Postgrd Med1991 July; $373,136-9$.

7. Soltan MH, Khashoggi T, Adelusi B. "Pregnancy following rupture of the pregnant uterus" Int J Gynaecol obstet 1996 January; 52:1, 37-42.

8. Peng JJ "30 years experience of obstetric hysterectomies" Zhonghua Fu Chan Ke Za Zhu 1991 November; 26: 6, 365-7. 